\title{
An Analysis of Students' Perspectives on the Usage of Knowledge Maps in Open Learning Environments
}

\author{
Heba Fasihuddin and Geoff Skinner
}

Received 31 Jan 2015 Accepted 20 Feb 2015

\begin{abstract}
Open learning is a new form of online learning that allows learning materials and courses to be freely available on the Internet and accessible to anyone who is interested. Massive Open Online Courses is the term used for courses provided in these open environments. The authors believe that open learning environments are still in their early stages of evolution in terms of providing effective learning models with many aspects still needing to be considered. These aspects can be addressed with consideration to principles of cognitive science and herein lies our research. Based on the concept of schema theory, the knowledge map has been chosen to organize and present learning concepts. This paper presents a study that has been held to evaluate the use of knowledge maps as an approach to presenting and organizing learning materials in open learning environments. A prototype has been developed and piloted on a group of IT students. The students' perspectives on the use of the knowledge maps and how they affect their learning have been collected through two surveys. The result is promising and an indication of the likely success of such an approach.
\end{abstract}

Keywords- Open Learning, knowledge Maps, Learning theories

\section{INTRODUCTION}

Online learning is an evolutionary learning approach that is evolving and changing due to the continuous evolution of technology. Open learning is a new phenomenon of online learning that allows learning materials to be freely available on the Internet to anyone who is interested. This new phenomenon has become a tangible reality due to the newly emerged cloud computing technology and ubiquitous networks. Cloud computing moves the computing infrastructure and data away from the users to the cloud and provides data and infrastructure on-demand as a service over the Internet by a third party.

In recent times, various prestigious learning institutions, such as Harvard, MIT, and Stanford, have utilized cloud computing to provide learning materials in an open approach. Coursera [1], edX [2], Udacity [3] and many others are all examples of this inventive open learning style. Courses that are provided through these open environments are known as Massive Open Online
Courses (MOOCs). Based on recent published figures, these courses attract an enormous registration rate and seem to be very popular [4]. However, the success of this learning approach is yet to be determined. It has been reported that the completion rate of MOOCs is very low, lower than $10 \%$. Although this might be due to reasons related to the learners' motivations to take and/or complete such courses, it raises questions and concerns regarding the success of the open learning approach. It has been found that the current format of MOOCs have some limitations that might affect their success and sustainability [5]. These limitations are related to many different aspects, such as teaching and learning methods, learning content, assessments, identity authentication, accreditation and learners' varying needs. All of these limitations raise different concerns about the sustainability of open learning. The authors believe that there is a need to enhance the current model of open learning and have found evidence that this can be done efficiently by considering cognitive science and learning principles [6].

This paper aims to introduce an approach to enhance the learning experience in open learning environments based on learning theories. It is believed that the organization and orientation of learning materials affect learners' conceptualization of learning contents and consequently the learning process. Therefore, the presented study in this paper focuses on enhancing the approach of organizing and presenting learning materials to support the self-regulated learning experience in the open learning environment where learners are in the role of organizing and learning at their own pace. Schema theory has been found to be effective in traditional learning [7]. Schemas are generally thought of as ways of incorporating instructions into our cognition. Schema theory has been described as the basic building blocks of knowledge and intellectual development that store concepts in human memory [7]. To apply the concept of schema theory, the use of knowledge maps, which are visual representations of knowledge that use different graphical shapes, was selected to present and organize learning materials [8]. This paper presents a study that was conducted to evaluate the usage of knowledge maps to organize learning materials in open learning environments. A prototype called Collaborative Adaptive Learning in the 
Cloud (CALC) has been developed and piloted on students from one of the Australian leading universities. An evaluation of students' perceptions on the use of knowledge maps and how they affect their learning is presented.

The rest of this paper is organized as follows. First, a background of open learning and contemporary MOOCs is provided in section 2. Following that, section 3 provides an overview of how learning theories, such as schema theory, can be applied to enhance models of open learning. Section 4 details the limitations of the study. Section 5 provides an overview of the study design including the prototype design, construction and development process. Next, the data collection details are provided in section 6 , with the results provided in section 7. Finally, the limitations of the study are highlighted and the paper is concluded.

\section{BACKGROUND}

\section{A. Open Learning}

As mentioned earlier the evolution of technology leads to continual changing and development in online learning approaches. Recently, open learning has emerged as a new form of online learning based on the utilization of cloud computing capabilities. In open learning, resources are freely available on the Internet to be accessed by anyone who is interested. These resources are provided by different learning providers who could be academics representing learning institutions or individuals who have appropriate knowledge and expertise. Recently, many academics have changed their practice by publishing their learning materials online and thus allowing their expertise to be accessed in an open form. This practice has gradually refined into what are known as Massive Open Online Courses (MOOCs). Open learning and the existence of MOOCs are dependent on certain main components. These components are as follows: Cloud Service Providers; Learning Providers; Learners.

\section{B. Massive Open Online Courses}

Massive Open Online Courses (MOOCs) are an emerged novel form of open learning that has developed based on recent contemporary computing technologies. MOOCs offer free university-level courses online and have two key features - open access and scalability [9]. These two features allow MOOCs to be taken online by anyone and enable them to be designed to support an indefinite or even infinite number of participants. MOOCs were originally constructed in 2008 by Stephen Downes and George Siemens who created the online course Connectivism and Connective Knowledge [10]. After that, a number of similar initiatives were established. Some of these initiatives are run in collaboration with prestigious educational institutions, such as Stanford, Harvard, and MIT, while others are by private organizations and individuals, such as Udemy [11]. These initiatives include Coursera [1], edX [2], Udacity [3], and others. All of these initiatives provide learning in an open, flexible form that allows anyone to take them up and learn. However, every learning provider has its own goals for initiating such a service and its own approaches to providing learning materials [12].

MOOCs represent a current controversial point and their success cannot be determined yet. Based on published figures, it seems that MOOCs are very popular with learners and learning institutions. For instance, it has been reported that Coursera has about 100 universities as partners from around 40 countries and more than $17,000,000$ enrolments from students representing 190 countries [13]. However while the first published course in edX got 154,763 registrations, only 8240 students have completed the course [4]. That makes the completion rate for that particular course about $5 \%$. In addition, it has been reported recently that in fact the completion rate for MOOCs is no more than $10 \%$ [4]. These figures have led to MOOCs becoming the subject of controversy and raise the questions of whether MOOCs are a sustainable educational model. Despite the low completion rate, it should be remembered that learners' motivations to take such courses differ and as such might be a reason for the lack of completions. In addition, in the current models there are no obligations on registrants to complete the course so this might also affect the completion rate. Aside from this, there are several other limitations of MOOCs that also impact their success and sustainability [5].

Based on the current status of MOOCs, it can be seen that there is no clear frontrunner in terms of a model for MOOCs or open learning environments. Rather MOOCs and other open learning initiatives are in their early stages of evolution. Different aspects still need to be considered and addressed in order to achieve a valid model. There is also the possibility that a single model might not be the solution for all learning needs and environments and a plethora of models and systems may emerge catering to differing learning needs and environments.

\section{CONSIDERING LEARNING THEORIES TO ENHANCE OPEN LEARNING OPPORTUNITIES}

Developing the online learning environment is a critical and sensitive field due to the implications for learners, instructors and the learning process. Therefore, principles for learning should be considered in the development of MOOCs in order to achieve the desired learning goals. This has been also recommended by Williams as he stated that tailoring general learning principles and working with cognitive scientists is one approach to consider to enhance MOOCs and provide the best outcomes for learners [6].

The authors believe that considering learning principles and cognitive science to address the known limitations will increase the opportunities of open learning. Learning in open learning environments is a self-regulated process; therefore it should support individual learners to learn independently in such a way that minimizes any possible obstacles to learning. One of the key factors to achieve this is the presentation and organization of learning materials. The authors' focus in this paper is to present an approach for organizing and presenting learning materials that simplifies the learning concepts and supports the learning process. The concept of schema theory has been found to be suitable and promising to achieve this 
aim and knowledge maps have been selected as the approach to apply schema theory. Following is an overview of schema theory and how it can be introduced in the open learning environment through the implementation of knowledge maps.

Schemas are generally thought of as ways of incorporating instructions into our cognition. Schema theory has been described as the basic building blocks of knowledge and intellectual development that store concepts in human memory [7]. According to Sweller [14], knowledge and related intellectual skills are heavily dependent on schema acquisition. In addition, it has been noted that an organizing schema is especially important for novice learners and essential for low ability learners [7]. Based on this reason, the authors found that learning concepts need to be presented in such a way that ensures the building of that schema in learners' memories and which consequently will assist in the learning process. Therefore, expert generated knowledge maps, which are designed by an expert in the field, were chosen as the most suitable approach to organize the presentation of learning concepts and materials.

Knowledge maps are a visual representation of knowledge that use different graphical shapes [8]. They represent an overview of specific knowledge by breaking the knowledge down into concepts that are related to each other. Concepts in knowledge maps are represented by ovals and the relationships between these concepts are represented by lines or arrows. These lines can be labelled or not [15]. Moreover, knowledge maps are often represented in a hierarchal structure with the most general concepts at the top of the hierarchy and the less general coming hierarchically lower. Another feature that can be found in some knowledge maps is cross-links, which represent the relationships between different concepts in different parts of the knowledge map.

\section{LIMITATIONS OF THE STUDY}

There are factors that might affect the results of the presented study. This study has been conducted on a programming course, so different courses and different learning concepts may affect the level of learners' satisfaction. In addition, because this study has been piloted on a core content course at the university it was not permissible through ethics to include a control group. This is due to the fact that applying a control group requires some changes on the course teaching methods, and thus there is perceived inequalities for different student groups over the duration of the course. Moreover, the sample of this study is a small sample which might affect the reported result. However, the median ratios of the findings were quite high and promising.

\section{RESEARCH DESIGN}

The research methodology for this study has been selected to fulfil the aim of the study, which is evaluating the impact of using knowledge maps on supporting the self-regulated independent learning process in open learning environments. Due to the nature of this research a mix of quantitative, qualitative and engineering research methods have been selected to achieve the desired aim.
First of all, we proposed to construct a prototype that simulates open learning environments while also incorporating knowledge maps to organize the learning concepts. This constructed prototype needed to be piloted and evaluated by real learners in order to get their feedback and perspectives about the usage of knowledge maps and whether it supported them in learning independently. Therefore it was proposed to conduct a pilot study on a course at the university and then ask the learners who participated in the study to provide their perspectives about their learning experience through surveys that involve some quantitative and qualitative questions. These questions were designed and chosen in alignment with the Technology Acceptance Model (TAM) [16], which is widely applied and utilized in IS research. TAM suggests that users' acceptance of a new technology is influenced by two factors: (a) perceived usefulness, and (b) perceived ease-of-use. The questions of both surveys were developed around these two factors so that required data can be collected for evaluation of our prototype.

The prototype for this study was developed as a website known as CALC. This website simulates open learning environments by providing free online learning materials that learners can access to learn independently at their own pace. In addition, this website is able to host many courses and the learning contents for these courses can be organized with knowledge maps. Although an initiative such as Udemy [11] allows anyone to teach and provide learning materials, it could not be adopted in this study as it does not fulfil the requirement of allowing learning materials to be organized with knowledge maps.

The development of knowledge maps has been grounded on computer-based knowledge maps. In a computer-based knowledge map every node representing a learning concept should link to a set of different, related learning resources by clicking an associated icon or hyperlink to that node. There are several tools to create digital knowledge maps, such as CmapTool [17], Knowledge Master [18] and Inspiration [19]. However, none of these tools were used to develop the knowledge maps in this study. This is because this study aims to foster the functionality of knowledge maps and how they support independent learning by adding assessment items along with the other learning resources to each node of the knowledge map so that every learner has the ability to assess their learning progress and track that on the knowledge map. The progress is reflected on the knowledge maps by colors, so successfully learnt and completed concepts/nodes are distinguished with a different color to the other nodes. We believe this will provide more support to the self-regulated independent learner.

\section{A. Prototype Design and Development}

The CALC prototype has been developed as a website using ASP.net technology. The website has two main phases. The first phase is for instructors where they can create courses, knowledge maps and add learning resources. The construction of knowledge maps in the prototype is done by inserting the course data manually as generating automatic knowledge maps is not within the scope of this study. Instructors have to insert the concept 
names one by one along with their dependencies to construct the knowledge maps. In order to reduce map shock, it was decided to break courses into topics and create knowledge maps for the topics instead of the courses. So, first, instructors have to create a course and its main topics. Then the knowledge map can be constructed for each topic by inserting the concept's name. After creating the knowledge maps, the learning resources and assessment items can be created for each concept. Learning resources are collected from different online sources and added to each concept so every concept has a list of hyperlinks to related learning materials. In regards to the assessment items, instructors are able to create multiple choice questions for each concept, so that every concept will have a set of questions which all together form a test bank.

The second phase is for the learners where they are able to access the various provided courses and learning resources. First, a learner needs to select a course and the desired topic under this course. After this selection the learner will get the learning concepts of this topic organized in a knowledge map. Every oval in the knowledge map represents a learning concept that can be clicked to access a list of hyperlinks that will guide the learner to a variety of learning resources for that particular concept. In addition, while the learner is on the concept page, he/she has the option to take a test to evaluate his/her learning progress, which the learner needs to be logged in to be able to take. After taking the test, the learner receives their result with a report that shows the state of each question with the option to show the right answers in cases where the answer was wrong. The concept is considered successfully completed if the test result is $50 \%$ or more and consequently its color is changed in the knowledge map from blue to green.

\section{B. Knowledge Map Construction}

The aim in this study is to utilize knowledge maps to support open learning environments for self-regulated learning by providing a full encapsulation for course contents to help learners, especially novice learners, to conceptualize the domain and the structure of the course. Using expert knowledge maps is believed to reduce misconceptualization and provide a solid foundation to start the course more effectively [20]. Therefore, the knowledge maps in this study were all created and reviewed by experts in the chosen fields.

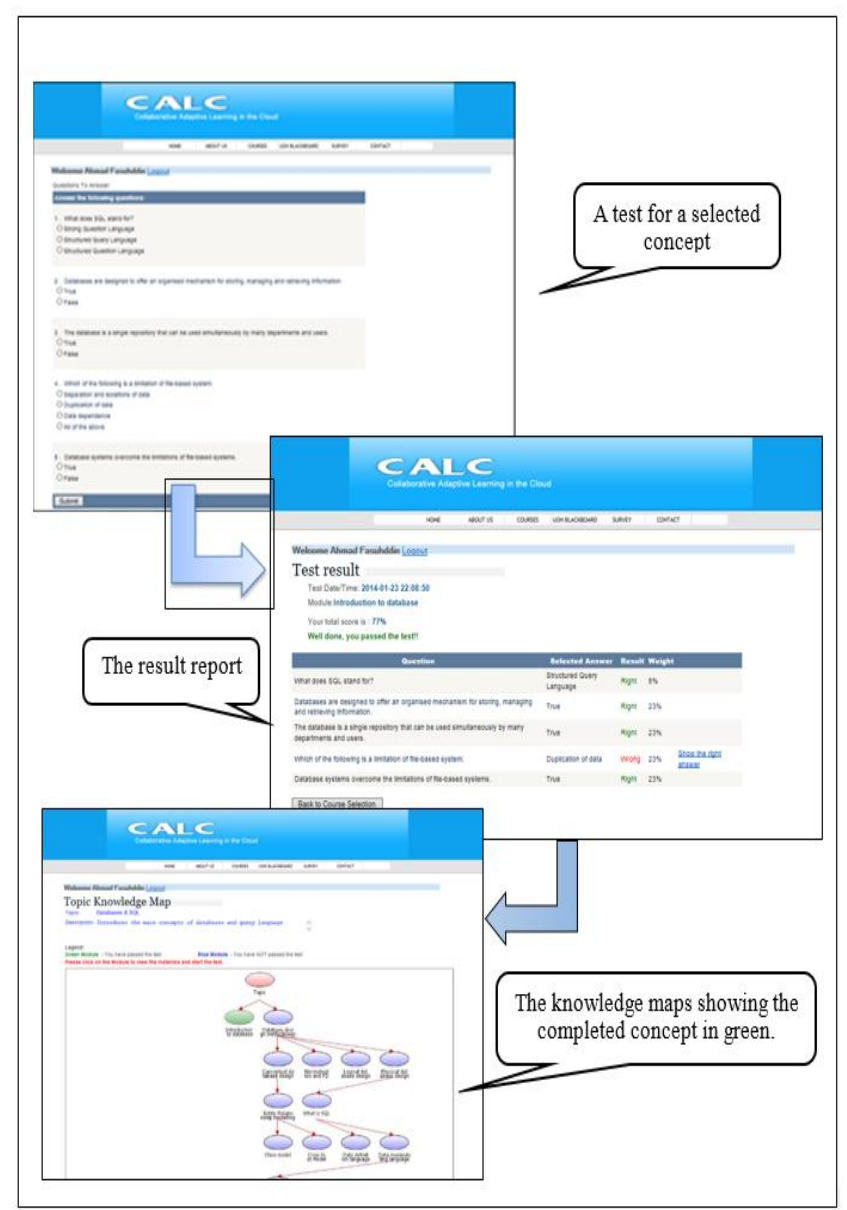

Figure 1: Screen shots of test, report and the updated knowledge map

Constructing the knowledge maps in this study has been done based on the process that was provided by Moore, Pierce, \& Williams [21] along with some additions by the authors. The applied process is as follows: 1) Locate an expert in the field who is familiar with teaching the course contents; 2) Divide the course into main topics in order to simplify the knowledge maps and reduce map shock; 3) Use textbooks and course syllabi to brainstorm the main concepts to be taught under each topic and record them as notes; 4) Group concepts that are usually taught together and label these groups; 5) Check for repeated concepts in groups and delete them; 6) In each group, organise concepts and link them based on their relationships to form small knowledge maps of each group; 7) Link the small knowledge maps together in order to form one topic knowledge map; and 8) Revise and refine the resultant knowledge map by discussing with other experts.

For the pilot, an ongoing programming course was selected from the undergraduate IT program at the university. Prerequisite materials for that course were hosted on the CALC website and divided into three main topics to simulate the proposed model of CALC, taking the map shock limitation into consideration. Students enrolled in the course were invited to access the learning materials and use the knowledge maps. The students were invited to use CALC for a week before the commencement of the semester. This gave them the opportunity to learn and 
explore the learning materials independently which is one of the key factors of this study.

\section{Learning Materials Collection}

As mentioned earlier the selected course for this study was a programming course, and specifically it was web programming that taught ASP.net based on C\#. Prerequisite materials for the course were organized into three main topics, being ASP.net, C\# and databases, which lead to three knowledge maps. The learning materials were collected from different online open sources by lecturers and researchers at the university who have sufficient expertise in those fields to assure the quality and accuracy of these learning materials. Moreover, a variety of learners' learning styles, were considered in the material collection so materials in different formats (i.e. text, video, lecture slides) were collected and included in the knowledge maps in order to suit the preferences of different learners - i.e. learning styles. According to Felder and Silverman [22] learning styles refer to the way a learner receives and processes information.

\section{Self Assessment Items}

The assessment items in the CALC website are multiple choice tests that allow learners to evaluate their learning for each concept. Sets of multiple choice questions were created for each concept by the experts who were involved in the learning material collection. The questions were weighted from 1 to 5 based on their importance and strength in relation to the concept, with 1 for the least strong to 5 for the most strong and important questions. This weight was designed in order to enhance the evaluation process so that better assessments could be achieved. Whenever a learner attempted a test for a concept, the test was generated with five randomly selected questions from the question bank for that concept. After the test was completed, the result was provided along with a detailed report that showed the weighted result of each question and whether it had been answered right or wrong.

\section{DATA COLLECTION}

The students who were invited to use the prototype and undertake the self-regulated learning experience using CALC were asked to provide their feedback through an online Likert scale survey. In addition, students were asked to provide their comments so as to collect qualitative data. The data collection was done in two stages: around the beginning of the semester and around the end of the semester. This was to compare whether students' perceptions differed before and after they had been taught by an instructor. The surveys were held to collect data and evaluate the learners' perceptions of different aspects, being the usage of knowledge maps, learning from open source materials and the self-assessment items, and how these impacted the learning process in such an independent self-regulated learning environment.

As mentioned earlier, the two surveys were held at two different times of the semester. The first survey was around the third week of the semester and 24 responses were collected. The second survey was around the end of the semester and 25 responses were collected. The participating students were diverse with their ages ranging from 20 up to 35 . Also, there were some participants with different native languages such as Indonesian and Korean. The surveys evaluated the different factors in terms of perceived of usefulness by asking several questions for each factor. The first factor was the use of knowledge maps and whether students found them helpful to organize learning materials and support their learning.

The survey questions for that factor were: (a) the organization of learning concepts in a knowledge map is helpful; (b) organizing learning concepts in a knowledge map structure supports my learning and helps me to visualize the course contents; and (c) providing URL links in the knowledge map is a useful resource management feature. Students provided their perception through a 5 point Likert scale survey where $1=$ strongly disagree and $5=$ strongly agree. For each survey, the collected data for these three questions was accumulated to calculate the overall learners' perception about the usage of knowledge maps. The analysis for both surveys shows a skewed data distribution with median $=4.33$ and interquartile range $=$ 1.33 for survey 1 , and median $=4.33$ and interquartile range $=1.00$ for survey 2 . The result of the collected data is promising and shows that most of the students agreed that the use of knowledge maps was beneficial for the learning process.

\section{RESULTS}

To compare between the result of the first and second survey and conclude whether the learners' perception about the knowledge maps had changed after they had been taught by an instructor, the Mann-Whitney nonparametric test was applied. The results showed that the difference was not statistically significant. Despite this result, both surveys shows that most students found the knowledge maps to be supportive to their learning.

The second factor that was evaluated by the students was the support for independent learning. The surveys had two questions that were concerned with this factor and these questions were: (a) using the prerequisite materials' model assists me to learn independently; and (b) the organization in knowledge maps helps me to learn independently. Similar to the previous factor, these two survey items were accumulated and the overall learners' perception about the impact of knowledge maps on their independent learning was calculated for both surveys (i.e. survey 1 and survey 2). The analysis of both surveys showed a skewed data distribution which indicates that most of the students agreed that the knowledge maps supported them to learn independently. For the first survey the median $=4$ and the interquartile range $=1.50$. For the second survey the median $=4.50$ and the interquartile range $=1.25$.

By applying the Mann-Whitney statistical test, it was found that the difference between the students' perception in the first and second surveys was not statistically significant. However, results showed learners' perception about the knowledge maps and how they support their independent learning has slightly increased in the second survey as compared to the first survey. 
In addition to the previous factors, students were also surveyed about their satisfaction on the self- assessment items and whether they helped them to assess their learning progress. Students were asked whether the provided self-assessments items were suitable for providing feedback on their learning needs. The results of both surveys show similar values for the median and the interquartile range on the 5 point Likert scale where $1=$ strongly disagree and $5=$ strongly agree. The resulting median $=4$ and interquartile range $=1$.

To evaluate the perceived ease-of use, students were asked whether the prototype was helpful and easy to use. For the first survey the median $=4$ and the interquartile range $=1.50$. For the second survey the median $=4$ and the interquartile range $=1$, and also the difference was not statistically significant. Furthermore, in the second survey students were asked whether they would like to use CALC in future learning and the resulting data shows a skewed distribution with median $=4$ and interquartile range $=1$. This is an indication that the incorporated features - the use of knowledge maps to organize learning contents along with the self-assessment items - were supportive for learners to learn in an open self-regulated learning environment.

In addition to the previously obtained data from the 5 point Likert scale questions, open ended questions were used to obtain qualitative feedback about the prototype implementation and pilot. The analysis of the qualitative data can be classified into two broad categories: (a) satisfactory responses and (b) feedback to improve the existing prototype. The satisfactory responses include highly positive feedback, such as: "The system is a fantastic idea and should be rolled out to other courses ...", "The system was interesting and engaging", "The CALC models were really helpful. I'd really like to use it again in future courses".

The feedback on improvements included bug fixes and suggestions for improvements such as “... useful ones to provide a snippet of information with the answers explaining why they were correct. It could be a useful touch to this program". The reported bugs have been fixed and some of the suggestions were implemented. Overall, the obtained findings were promising and a positive indication that the proposed approach can be considered as a successful design for open learning environments.

\section{CONCLUSION}

This paper introduces a study that aims to increase the opportunities for open learning. In open learning environments online courses are offered for free to be accessed by any interested learner. Recently, many prestigious learning institutions have implemented this form of learning and offer free courses that are known as Massive Open Online Courses (MOOCs).The authors believe that the models for open learning environments and MOOCs are still in their early stages of evolution and many aspects still need to be considered and addressed in order to achieve an effective and sustainable model. It has been found that applying cognitive science and learning principles can maximize the outcomes of MOOCs and increase their opportunities to be sustainable [6].
The focus of this paper has been to introduce an approach for organizing and presenting learning materials that is able to support the process of self-regulated learning. Based on schema theory, knowledge maps (a graphical representation of learning concepts) were selected to organize and present learning materials as this is an approach that can help in building a schema of learning concepts in learners' memories and consequently assist them in the learning process.

A prototype has been developed as a website that simulates the open learning environment. This website is called CALC and it provides learning concepts and materials organized in knowledge maps. The prototype was piloted on a course at a leading Australian university and prerequisite materials were provided for that course. The provided prerequisite materials were collected and organized in knowledge maps by experts from the university. The students who were enrolled in the selected course were invited to try the prototype before the beginning of the semester so that they had the opportunity to browse the learning materials at their own pace, as is the case with the open learning environment. Then the students were invited to participate in online surveys to provide their perceptions about the use of knowledge maps and how they found these impacted on their learning process. A total of 49 students filled in the surveys and provided their feedback. Data was collected, analyzed and reported in this paper. Despite the fact that this study was piloted on a small sample, the result is promising and can be taken as an indication that knowledge maps are a suitable approach to organize content that support the learning process in open learning environments.

\section{REFERENCES}

[1] Coursera. (2012). Coursera. Retrieved 25-7-2012 from https://www.coursera.org/

[2] edX. (2012). edX. Retrieved 26-5-2012 from http://www.edxonline.org/

[3] Udacity. (2012). Meet Udacity! from http://www.udacity.com/

[4] Breslow, L. B., Pritchard, D. E., DeBoer, J., Stump, G. S., Ho, A. D., \& Seaton, D. T. (2013). Studying learning in the worldwide classroom: Research into edX's first MOOC. Research \& Practice in Assessment, 8, 13-25.

[5] Roberts, J. J., \& O'Loughlin, J. (2013). The season of the MOOC. UNIversitas, 8. http://www.uni.edu/universitas

[6] Williams, J. J. (2013). Improving learning in MOOCs with cognitive science. Paper presented at the AIED 2013 Workshops Proceedings Volume

[7] Chalmers, P. A. (2003). The role of cognitive theory in humancomputer interface. Computers in Human Behavior, 19(5), $593-$ 607.

[8] Li-Yu, L., Yu-Shih, L., \& Chih-Ping, C. (2012). Constructing personal concept map automatically via correlative test-items structure. The Information Technology Based Higher Education and Training (ITHET), 2012 International Conference, 21-23 June 2012

[9] Yuan, L., \& Powell, S. (2013). MOOCs and open education: Implications for higher education. CETIS JISC, 21, 2013.

[10] Parr, C. (2013). MOOC creators criticise courses' lack of creativity. Times Higher Education. Retrieved 5-11-2013 from http://www.timeshighereducation.co.uk/news/mooc-creatorscriticise-courses-lack-of-creativity/2008180.fullarticle.

[11] Udemy. (2014). Udemy. Retrieved 22-1-2014 from https://www.udemy.com/

[12] Fasihuddin, H., Skinner, G., \& Athauda, R. (2012). A review of contemporary cloud based E-learning initiatives. Paper presented 
at the IADIS International Conference on Internet Technologies \& Society, Perth, Australia.

[13] Lewin, T. (2013). U.S teams up with operator of online courses to plan a global network. The New York Times. Retrieved 5-11-2013 from http://www.nytimes.com/2013/11/01/education/us-plansglobal-network-of-free-online-courses.html?_r=1\&.

[14] Sweller, J. (1994). Cognitive load theory, learning difficulty, and instructional design. Learning and Instruction, 4(4), 295-312.

[15] Coffey, J. (2005). LEO: A concept map based course visualization tool for instructors and students. In S.-O. Tergan \& T. Keller (Eds.), Knowledge and Information Visualization (Vol. 3426, pp. 285-301): Springer Berlin Heidelberg.

[16] Davis, F. D. (1989). Perceived usefulness, perceived ease of use, and user acceptance of information technology. MIS quarterly, 319-340.

[17] Institute for Human and Machine Cognition (IHMC). (2013) IHMC Cmap Tool. Retrieved 5/12/2013 from http://cmap.ihmc.us/

[18] KnowledgeMaster. (2011). Knowledge Master. Retrieved 22/1/2014 from http://www.knowledgemanager.us/default-eng.htm

[19] Inspiration. (2014). Inspiration Software Incorporation. Retrieved 22/1/2014 from http://www.inspiration.com/

[20] Wang, M., Peng, J., Cheng, B., Zhou, H., \& Liu, J. (2011). Knowledge visualization for self-regulated learning. Educational Technology \& Society, 14(3), 28-42.

[21] Moore, J. P., Pierce, R. S., \& Williams, C. B. (2012). Towards an "Adaptive Concept Map": Creating an expert-generated concept map of an engineering statics curriculum. Paper presented at the American Society for Engineering Education.

[22] Felder, R. M., \& Silverman, L. K. (1988). Learning and teaching styles in engineering education. Engineering education, 78(7), 674681.To DoKhan Academy. (2012).

\section{AUTHORS' PROFILE}

Dr Geoff Skinner is Head of the IT Discipline at the University of Newcastle, and member of the Priority Research Centre for Physical Activity and Nutrition. He has close to 100 International peer reviewed publications and 2 book chapters in the field of Data Security. Coupled with over 15 years professional Industry experience, he brings a wealth of knowledge to his chosen research domains. These include Active Living Technologies, Exertainment, Data and Information Security, and eLearning.

Heba Fasihuddin is a $\mathrm{PhD}$ candidate at the University of Newcastle. She is sponsored by King Abdulaziz University in Saudi Arabia in which she is employed. To date Heba published more than 10 peer-reviewed scientific publications. Her research interests include adaptive learning and technology enhanced learning

This article is distributed under the terms of the Creative Commons Attribution License which permits any use, distribution, and reproduction in any medium, provided the original author(s) and the source are credited. 